\title{
$B R A F$ mutations in anaplastic thyroid carcinoma: implications for tumor origin, diagnosis and treatment
}

\author{
Shahnaz Begum ${ }^{1, *}$, Eli Rosenbaum ${ }^{2, *}$, Rui Henrique ${ }^{3}$, Yoram Cohen ${ }^{3}$, David Sidransky ${ }^{1,2,3}$ \\ and William H Westra ${ }^{1,2,3}$ \\ ${ }^{1}$ Department of Pathology; ${ }^{2}$ Department of Oncology and ${ }^{3}$ Department of Otolaryngology, Head and Neck \\ Surgery (Division of Head and Neck Cancer Research), The Johns Hopkins Medical Institutions, Baltimore, \\ $M D, U S A$
}

\begin{abstract}
Anaplastic thyroid carcinoma is a highly aggressive neoplasm. Affected patients typically present with advanced disease where there is little hope for cure using conventional therapeutic modalities. Understanding the genetic alterations underlying the development of anaplastic thyroid carcinoma, such as mutational activation of BRAF, could help clarify its relationship with well-differentiated forms of thyroid carcinoma (ie follicular and papillary carcinoma) and could help select patients most likely to benefit from novel therapeutic strategies targeting BRAF. We tested 16 anaplastic thyroid carcinomas for the thymine $(T) \rightarrow$ adenine $(A)$ missense mutation at nucleotide 1796 in the BRAF gene using a newly developed assay that employs a novel primer extension method (Mutector ${ }^{\mathbb{B}}$ assay). Seven of these anaplastic thyroid carcinomas arose in association with a well-differentiated thyroid carcinoma, and these were also evaluated. The $1796 \mathrm{~T} \rightarrow \mathrm{A}$ mutation was detected in eight $(50 \%)$ of the anaplastic thyroid carcinomas, in four of five $(80 \%)$ associated papillary thyroid carcinomas, and in zero of two (0\%) associated follicular carcinomas. In all seven cases where anaplastic thyroid carcinoma arose in association with a well-differentiated thyroid carcinoma, BRAF status in the two components was concordant. Like papillary thyroid carcinoma, a significant percentage of anaplastic thyroid carcinomas also harbor BRAF mutations. Indeed, when papillary thyroid carcinoma and anaplastic thyroid carcinoma occur together, they consistently share the same BRAF profile, supporting the notion that many anaplastic thyroid carcinomas actually represent progressive malignant degeneration of a pre-existing welldifferentiated thyroid carcinoma. The high frequency of $B R A F$ mutations in a tumor that is generally regarded as uniformly fatal justifies evaluation of the potential benefits of anti-BRAF therapy for patients with anaplastic thyroid carcinoma.
\end{abstract}

Modern Pathology (2004) 17, 1359-1363, advance online publication, 11 June 2004; doi:10.1038/modpathol.3800198

Keywords: thyroid cancer; oncogene; tyrosine kinase; mitogen activated protein kinase

It has long been suspected that anaplastic thyroid carcinoma embodies an ultimate and conclusive stage in thyroid tumorigenesis, and that a welldifferentiated thyroid carcinoma (ie papillary and follicular carcinoma) serves as an antecedent and requisite step in that progression. ${ }^{1}$ Yet, despite the presumed close relationship between well-differentiated thyroid carcinoma and its anaplastic counterpart, the contrast between the two is striking. Clinically, anaplastic thyroid carcinoma is a highly

Correspondence: Dr WH Westra, MD, The Weinberg Building, Room 2242, 401 N. Broadway, Baltimore, MD 21231, USA.

E-mail: wwestra@jhmi.edu

*These authors contributed equally to this work.

Received 24 March 2004; revised and accepted 6 April 2004; published online 11 June 2004 aggressive and rapidly fatal. For most patients, complete surgical resection is not possible, and radiation and chemotherapy is not effective. ${ }^{2}$ At the microscopic and immunohistochemical level, anaplastic thyroid carcinoma shows no evidence of thyroid follicular differentiation and, in many instances, little if any evidence of epithelial differentiation. In these undifferentiated tumors, distinction from a sarcoma is difficult if not impossible using conventional histologic and immunohistochemical techniques. ${ }^{3,4}$ At the genetic level, anaplastic thyroid carcinoma demonstrates advanced genetic alterations. Compared to well-differentiated carcinomas, anaplastic thyroid carcinomas are more likely to be aneuploid, ${ }^{5}$ they demonstrate a much higher prevalence of loss of heterozygosity, ${ }^{1,6}$ and they harbor alterations of key regulators of cell 
growth and differentiation that are not targeted in earlier stages of tumorigenesis. ${ }^{7,8}$ As one example, mutations of p53 are commonly noted in anaplastic thyroid carcinomas, but they are rarely present in well-differentiated thyroid carcinomas. ${ }^{9-12}$

$B R A F$ encodes a serine-threonine kinase that acts in the mitogen activated protein kinase (MAPK) pathway. ${ }^{13}$ Activating $B R A F$ mutations induce constitutive activation of the signal transduction pathway, providing a potent promitogenic force that drives malignant transformation. ${ }^{14,15}$ Activating mutations of the BRAF oncogene is the most common genetic alteration in well-differentiated thyroid carcinoma, but this alteration is highly tumor-type specific. BRAF mutations are identified in the majority of conventional papillary thyroid carcinomas, but they are uniformly absent in follicular carcinomas. ${ }^{16-20}$ Studies addressing the frequency of $B R A F$ mutations in undifferentiated thyroid carcinomas are much more limited. In one recent study addressing the frequency of $B R A F$ mutations across all grades of thyroid carcinoma, only $10 \%$ of anaplastic thyroid carcinomas harbored $B R A F \mathrm{mu}-$ tations. ${ }^{21}$

In the present study, we evaluated anaplastic thyroid carcinomas and, when present, associated well-differentiated thyroid carcinomas for the presence of $B R A F$ mutations. Uncovering of a frequent target of mutational activation in this highly aggressive form of thyroid carcinoma could (1) clarify the relationship between well-differentiated and de-differentiated forms of thyroid carcinoma, (2) help distinguish anaplastic thyroid carcinoma from other types of poorly differentiated neoplasms, and (3) potentially identify a target for novel therapies directed against pathways of deregulated cell growth.

\section{Patients and methods}

\section{Sample Selection and DNA Isolation}

In all, 16 patients with anaplastic thyroid carcinoma were identified from a search of the archival surgical pathology files of The Johns Hopkins Hospital between 1985 and 2003. After initial patient identification, all original histologic slides were reviewed by one of us (WHW) to confirm the diagnosis, and an appropriate block was retrieved for DNA extraction. The paraffin blocks were sectioned, and tissues sections were microdissected to obtain greater than $80 \%$ neoplastic cells. When the slides showed an anaplastic thyroid carcinoma arising in association with a well-differentiated thyroid carcinoma, the anaplastic and well-differentiated components were separately collected and analyzed. DNA was extracted using standard protocols as previously published. ${ }^{22}$

\section{Detection of BRAF Mutations}

All tumor samples and controls were analyzed for the thymine $(\mathrm{T}) \rightarrow$ adenine (A) missense mutation at nucleotide 1796 in the $B R A F$ gene. This hot spot was chosen because the reported $B R A F$-activating mutations in thyroid carcinomas occur almost exclusively at this position. ${ }^{18,21,23}$ Polymerase chain reaction (PCR) primer sequences were designed to amplify a $102 \mathrm{bp}$ fragment of exon $15\left(5^{\prime}\right.$-GAA GAC CTC ACA GTA AAA ATA GGT GA-3', and 5'- CCA CAA AAT GGA TCC AGA CA-3'). PCR amplification was performed using $100 \mathrm{ng}$ of tumor sample DNA as template. The PCR reactions were carried out in a 96-well thermocycler. Cycling conditions were as follows: a denaturation step at $95^{\circ} \mathrm{C}$ for $5 \mathrm{~min}$ was followed by two cycles of denaturation at $95^{\circ} \mathrm{C}$ for $1 \mathrm{~min}$, annealing at $60^{\circ} \mathrm{C}$ for $1 \mathrm{~min}$, primer extension at $72^{\circ} \mathrm{C}$ for $1 \mathrm{~min}$, two cycles of denaturation at $95^{\circ} \mathrm{C}$ for $1 \mathrm{~min}$, annealing at $58^{\circ} \mathrm{C}$ for $1 \mathrm{~min}$, primer extension at $72^{\circ} \mathrm{C}$ for $1 \mathrm{~min}, 35$ cycles of denaturation at $95^{\circ} \mathrm{C}$ for $1 \mathrm{~min}$, annealing at $56^{\circ} \mathrm{C}$ for $1 \mathrm{~min}$, primer extension at $72^{\circ} \mathrm{C}$ for $1 \mathrm{~min}$, and one final extension at $72^{\circ} \mathrm{C}$ for $5 \mathrm{~min}$. Amplified fragments were separated on an agarose gel and visualized by ethidium bromide staining.

Analysis of the PCR products for a $B R A F$ mutation at nucleotide position 1796 was performed using the Mutector ${ }^{\circledR}$ assay (TrimGen, Sparks, MD, USA). The Mutector ${ }^{\mathbb{B}}$ assay is designed for the detection of any type of known DNA mutation. ${ }^{24}$ In brief, a detection primer is designed that does not permit primer extension when the target base is wild type. As a result, primer extension does not occur, labeled nucleotides are not incorporated, and a color reaction is not observed. When the target base is mutated (eg $\mathrm{T} \rightarrow \mathrm{A}$ transversion at BRAF T1796), primer extension continues and a strong color reaction is observed. We used as a template $10-\mu \mathrm{l}$ of PCR products of the $102 \mathrm{bp}$ fragment of $B R A F$ exon 15. The assay was preformed according to the manufacturer's instructions. When we previously compared BRAF detection for a large number of human tumors, we found a $100 \%$ correlation between the Mutector ${ }^{\circledR}$ assay and direct sequencing (unpublished results).

As a positive control for the BRAF T1796A mutation, we tested the cutaneous melanoma cell line HTB 72. The cervical cancer cell line ME180, known to be wild type for BRAF at T1796, served as a negative control.

\section{Results}

In all, 16 patients with anaplastic thyroid carcinomas were identified through a search of the archival surgical pathology files, and these formed the basis of this study. The relevant clinical, pathologic and genetic features are summarized in Table 1. Nine of the patients were female and seven were male. The median age was 65 years (mean, 65 years; range, 51-83 years). When further subclassified by the predominant histologic pattern (Figure 1), six of the anaplastic thyroid carcinomas were giant cell, six 
Table 1 Summary of clinicopathologic features and $B R A F$ status

\begin{tabular}{|c|c|c|c|c|c|c|}
\hline \multirow{3}{*}{$\begin{array}{l}\text { Case } \\
\#\end{array}$} & \multirow[t]{3}{*}{ Age } & \multirow[t]{3}{*}{ Gender } & \multirow[t]{3}{*}{ Variant } & \multicolumn{3}{|c|}{ BRAF status } \\
\hline & & & & \multirow[t]{2}{*}{$\begin{array}{l}\text { Undifferen- } \\
\quad \text { tiated }\end{array}$} & \multicolumn{2}{|c|}{$\begin{array}{c}\text { Well } \\
\text { differentiated }\end{array}$} \\
\hline & & & & & PTC & FTC \\
\hline 1 & 64 & $\mathrm{~F}$ & Giant cell & wt & - & wt \\
\hline 2 & 51 & $\mathrm{M}$ & Squamoid & $\mathrm{T} \rightarrow \mathrm{A}$ & - & - \\
\hline 3 & 64 & $\mathrm{~F}$ & Giant cell & wt & - & - \\
\hline 4 & 52 & $\mathrm{M}$ & Spindled & $\mathrm{T} \rightarrow \mathrm{A}$ & - & - \\
\hline 5 & 61 & $\mathrm{~F}$ & Squamoid & $\mathrm{T} \rightarrow \mathrm{A}$ & $\mathrm{T} \rightarrow \mathrm{A}$ & - \\
\hline 6 & 68 & $\mathrm{~F}$ & Giant cell & wt & - & - \\
\hline 7 & 53 & $\mathrm{M}$ & Spindled & wt & - & - \\
\hline 8 & 53 & $\mathrm{~F}$ & Giant cell & wt & - & wt \\
\hline 9 & 72 & $\mathrm{~F}$ & Squamoid & wt & - & - \\
\hline 10 & 66 & $\mathrm{M}$ & Giant cell & $\mathrm{T} \rightarrow \mathrm{A}$ & - & - \\
\hline 11 & 75 & $\mathrm{~F}$ & Spindled & wt & wt & - \\
\hline 12 & 75 & $\mathrm{~F}$ & Spindled & $\mathrm{T} \rightarrow \mathrm{A}$ & $\mathrm{T} \rightarrow \mathrm{A}$ & - \\
\hline 13 & 71 & $\mathrm{M}$ & Spindled & wt & - & - \\
\hline 14 & 73 & $\mathrm{M}$ & Squamoid & $\mathrm{T} \rightarrow \mathrm{A}$ & $\mathrm{T} \rightarrow \mathrm{A}$ & - \\
\hline 15 & 60 & $\mathrm{~F}$ & Giant cell & $\mathrm{T} \rightarrow \mathrm{A}$ & - & - \\
\hline 16 & 83 & $\mathrm{M}$ & Spindled & $\mathrm{T} \rightarrow \mathrm{A}$ & $\mathrm{T} \rightarrow \mathrm{A}$ & - \\
\hline
\end{tabular}

were spindled, and four were squamoid. Seven of the 16 anaplastic thyroid carcinomas $(44 \%)$ were associated with a well-differentiated thyroid carcinoma. In five cases, the well-differentiated carcinoma was papillary thyroid carcinoma (Figure 2a), and in two cases the well-differentiated component was follicular carcinoma.

$B R A F$ mutations were detected in eight of the 16 $(50 \%)$ anaplastic thyroid carcinomas. As for the associated well-differentiated thyroid carcinomas, $B R A F$ mutations were detected in four of the five $(80 \%)$ papillary thyroid carcinomas, but in none of the two $(0 \%)$ follicular carcinomas. In all eight cases where anaplastic thyroid carcinoma arose in association with a well-differentiated thyroid carcinoma, both components showed the same $B R A F$ profile (100\% concordance) (Table1 and Figure 2).

\section{Discussion}

Thyroid carcinoma is a disease of extremes. The follicular and papillary carcinomas tend to be morphologically well-differentiated, clinically indolent, and readily cured by a combination of surgical resection and radioactive iodine administration. ${ }^{25}$ At the other end of the spectrum, anaplastic thyroid carcinoma is morphologically undifferentiated, clinically aggressive, and fatal in most cases notwithstanding hard-hitting multimodality therapy. ${ }^{1,2}$ The relationship between well-differentiated and undifferentiated thyroid carcinoma has long been a point of interest. The current consensus holds that most, if not all, anaplastic thyroid carcinomas arise from a pre-existing well-differentiated thyroid carcinoma. This notion is largely based on the circumstantial evidence that anaplastic thyroid carcinoma is sometimes topographically associated with a well-differentiated thyroid carcinoma. In reported series, anywhere from 8 to $90 \%$ of anaplastic thyroid carcinomas are seen in association with a differentiated carcinoma. ${ }^{1,3}$ The direct and casual relationship between well-differentiated and undifferentiated thyroid carcinoma, however, has not been convincingly confirmed at the molecular genetic level. With their complex karyotypes and extensive allelic imbalances, anaplastic thyroid carcinomas show little resemblance to well-differ-
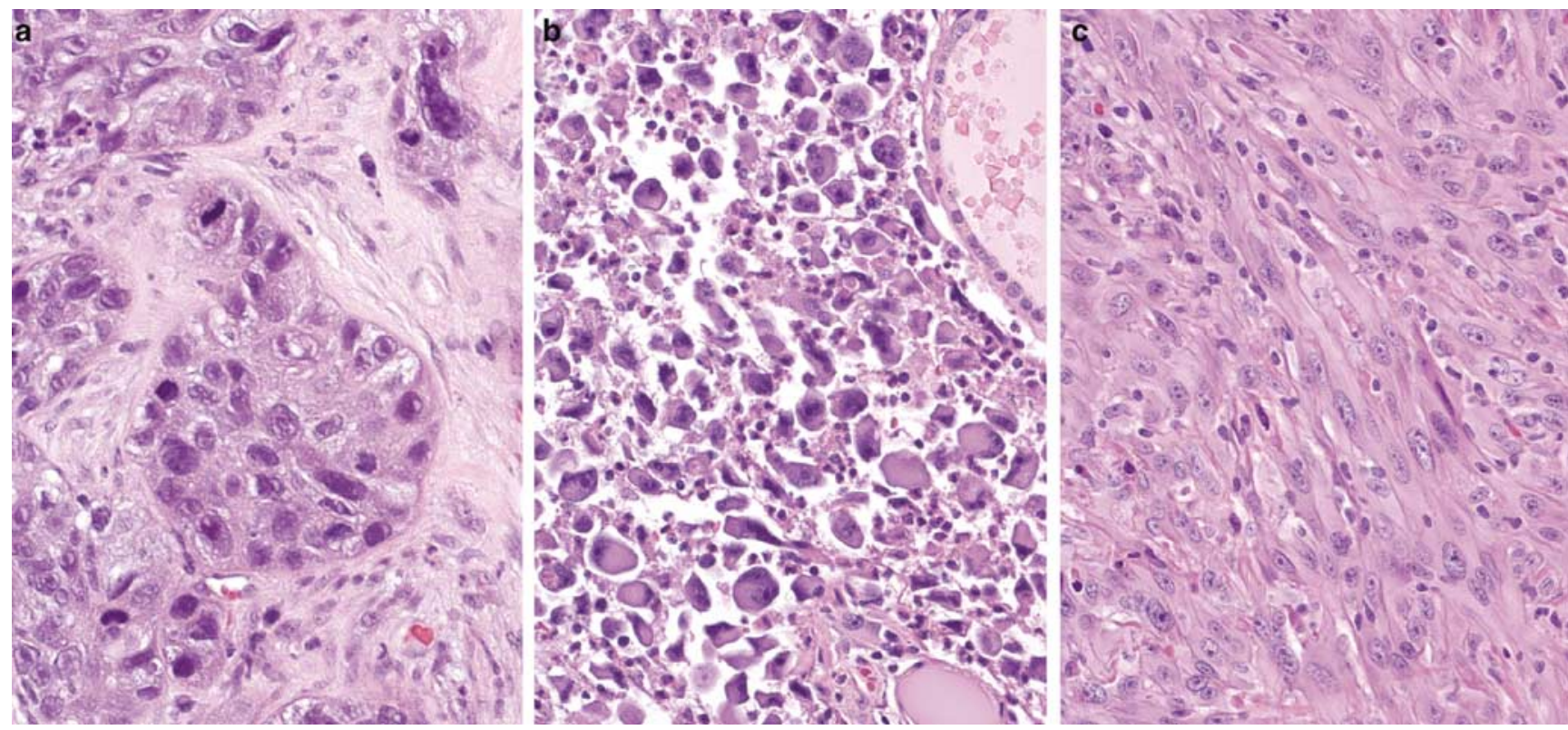

Figure 1 Microscopic appearance of anaplastic thyroid carcinoma is highly variable. Frequently encountered patterns include squamoid (Case 14) (a), giant cell (Case 6) (b), and spindle cell (Case 11) (c). 


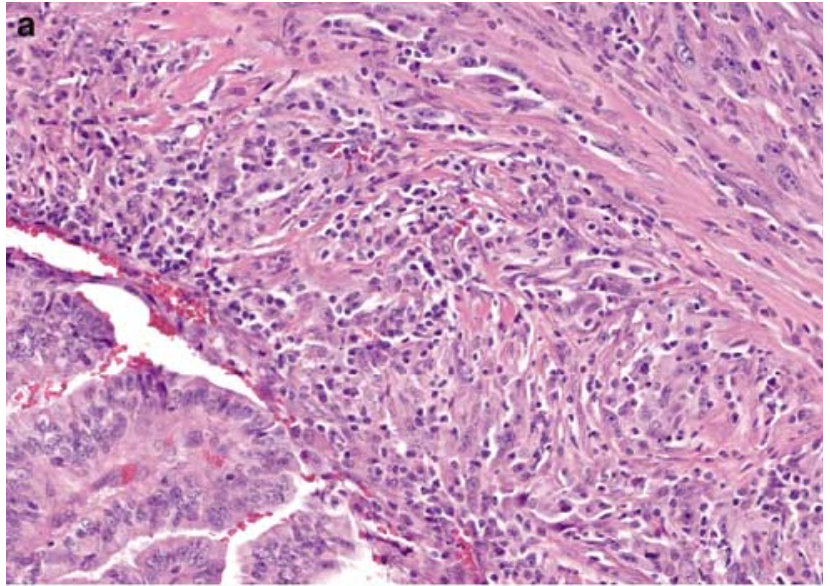

b

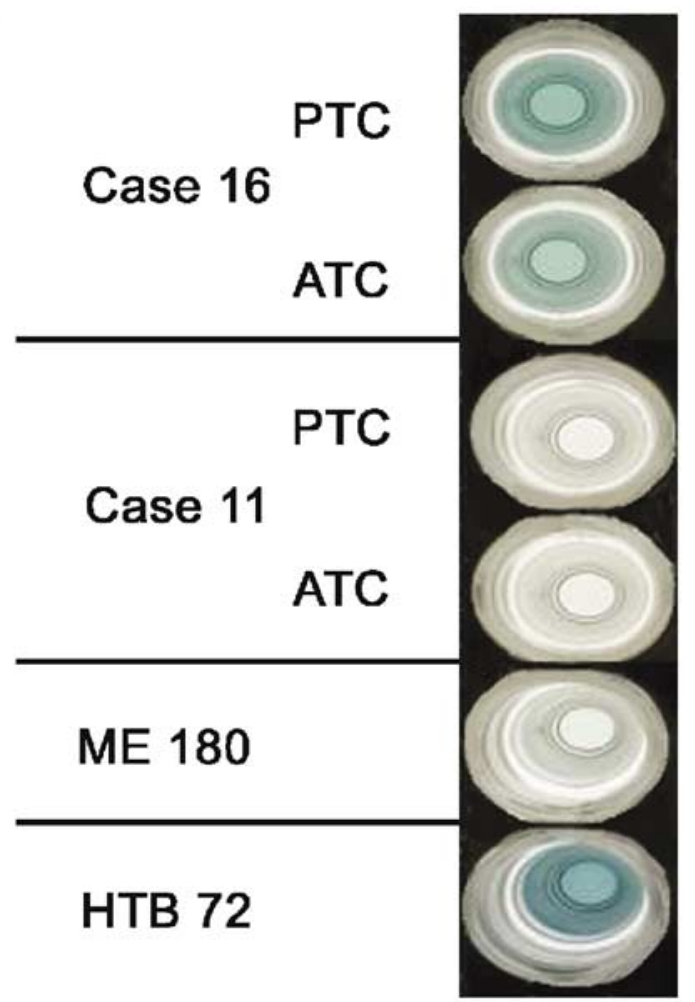

Figure 2 Case 16 is seen microscopically as an anaplastic thyroid carcinoma (a, right) arising in association with a papillary thyroid carcinoma (a, lower left). Using the Mutector ${ }^{\circledR}$ assay, the presence of a $B R A F$ mutation, as indicated by a colorimetric change from clear to green, is noted in both tumor components from Case 16; while wild-type $B R A F$, as indicated by the absence of a colorimetric reaction, is noted in both tumor components from Case 11 (b). The controls used include the ME 180 cervical cell line (wild-type for $B R A F$ ), and the HTB 72 melanoma cell line (homozygous for the $\mathrm{T} \rightarrow \mathrm{A}$ transversion at T1796). (ATC, anaplastic thyroid carcinoma; PTC, papillary thyroid carcinoma).

entiated thyroid carcinoma, leading some investigators to conclude that anaplastic thyroid carcinomas arise de novo. ${ }^{5}$

Like conventional papillary thyroid carcinoma, we found that a significant percentage (ie 50\%) of anaplastic thyroid carcinomas also harbor activating point mutations of the BRAF oncogene. Comparative mutational analysis of anaplastic thyroid carcinoma arising in association with well-differentiated thyroid carcinoma was helpful in clarifying the relationship of these distinct components: anaplastic thyroid carcinomas and their paired differentiated carcinomas consistently harbored the same BRAF profile, providing genetic support for the notion that anaplastic thyroid carcinomas arise directly from a pre-existing well-differentiated thyroid carcinoma. Along these same lines, Nikiforova et $a l^{21}$ noted that $B R A F$ mutations in anaplastic thyroid carcinomas are restricted to those tumors arising in association with $B R A F$-mutated papillary thyroid carcinomas. While at least some anaplastic thyroid carcinomas do indeed represent dedifferentiation of a differentiated thyroid carcinoma, activating $B R A F$ mutations do not appear to trigger this transformation. In contrast to other important genetic alterations such as p53 inactivation, ${ }^{9-12}$ BRAF mutations do not newly emerge in anaplastic thyroid carcinomas arising from well-differentiated carcinomas that do not harbor $B R A F$ mutations. Instead, activating $B R A F$ mutations appear to be a relatively early and stable event in thyroid tumorigenesis.

As a tumor that is often undifferentiated by light microscopy and even by immunohistochemistry, anaplastic thyroid carcinomas are difficult to distinguish from other poorly differentiated tumors in the neck. The distinction between the spindled and giant cell subtypes of anaplastic thyroid carcinoma and high-grade sarcoma is particularly treacherous, and in many such instances the diagnosis of anaplastic thyroid carcinoma is tentatively presumed rather than definitely established using conventional diagnostic techniques. ${ }^{3}$ Genetic analysis for BRAF mutations offers much promise as a useful diagnostic tool. In contrast to the high frequency of $B R A F$ mutations in anaplastic thyroid carcinoma, Davies et $a l^{14}$ detected a $B R A F$ mutation in only one of $182(0.5 \%)$ of the primary sarcomas they evaluated. Moreover, the newly developed Mutector ${ }^{\circledR}$ assay ${ }^{24}$ permits automated $B R A F$ analysis that is accurate, objective, and rapid. We previously noted complete concordance when results obtained by the Mutector ${ }^{\mathbb{B}}$ assay are compared with those obtained by direct sequencing for a large number of thyroid carcinomas (personal observations). In effect, BRAF mutational analysis is straightforward and amendable to transfer from the research bench to the diagnostic laboratory as a tool to supplement traditional diagnostic methods.

Molecular targeting of tyrosine kinases is rapidly emerging as a novel strategy for treating various human cancers. Indeed, several molecule inhibitors that are specific to individual receptor tyrosine kinases have been developed, and a number of these potential anticancer agents-including inhibitors of key constituents in the MAP kinase pathway-are progressing through clinical trials. ${ }^{26,27}$ Even though papillary thyroid carcinomas frequently harbor $B R A F$ mutations, patients with papillary thyroid carcinoma may have little to 
benefit from anti-BRAF therapy. As a group, these patients have an excellent prognosis and respond well to current therapies. At the other extreme, anaplastic thyroid carcinomas do not respond to current therapies and patients with anaplastic thyroid carcinoma almost always die of their disease. Clearly, this small but important subgroup of patients with thyroid cancer would most benefit from novel therapeutic alternatives. Given that anaplastic thyroid carcinomas frequently harbor activating mutations of the $B R A F$ oncogene, therapeutic agents targeting the activated $B R A F$ pathway is one particularly compelling strategy.

\section{Acknowledgement}

This project was funded by the National Institutes of Health (P50 CA96784-01).

\section{References}

1 Wiseman SM, Loree TR, Rigual NR, et al. Anaplastic transformation of thyroid cancer: review of clinical, pathologic, and molecular evidence provides new insights into disease biology and future therapy. Head Neck 2003;25:662-670.

2 Pasieka JL. Anaplastic thyroid cancer. Curr Opin Oncol 2003;15:78-83.

3 Rosai J, Carcangiu ML, DeLellis RA. Undifferentiated (anaplastic) carcinoma. In: Rosai J, Carcangiu ML, DeLellis RA (eds). Tumors of the Thyroid Gland, 3rd Series. Armed Forces Institute of Pathology: Washington DC, 1990, pp 135-159.

4 LiVolsi VA, Brooks JJ, Arendash-Durand B. Anaplastic thyroid tumors: Immunohistology. Am J Clin Pathol 1987;87:434-442.

5 Wallin G, Backdahl M, Tallroth-Ekman E, et al. Coexistent anaplastic and well differentiated thyroid carcinomas: a nuclear DNA study. Eur J Surg Oncol 1989;15:43-48.

6 Hunt JL, Tometsko MT, LiVolsi VA, et al. Molecular evidence of anaplastic transformation in coexisting well-differentiated and anaplastic carcinomas of the thyroid. Am J Surg Pathol 2003;27:1559-1564.

7 Frisk T, Foukakis T, Dwight T, et al. Silencing of the PTEN tumor-suppressor gene in anaplastic thyroid cancer. Genes Chromosomes Cancer 2002;35:74-80.

8 Wreesmann VB, Ghossein RA, Patel SG, et al. Genomewide appraisal of thyroid cancer progression. Am J Pathol 2002;161:1549-1556.

9 Nakamura T, Yana I, Kobayashi T, et al. p53 gene mutations associated with anaplastic transformation of human thyroid carcinomas. Jpn J Cancer Res 1992;83: 1293-1298.

10 Fagin JA, Matsuo K, Karmakar A, et al. High prevalence of mutations of the p53 gene in poorly differentiated human thyroid carcinomas. J Clin Invest 1993;91:179-184.
11 Donghi R, Longoni A, Pilotti S, et al. Gene p53 mutations are restricted to poorly differentiated and undifferentiated carcinomas of the thyroid gland. J Clin Invest 1993;91:1753-1760.

12 Fagin JA. Tumor suppressor genes in human thyroid neoplasms: p53 mutations are associated undifferentiated thyroid cancers. J Endocrinol Invest 1995;18: 140-142.

13 Peyssonnaux C, Eychene A. The Raf/MEK/ERK pathway: new concepts of activation. Biol Cell 2001;93:53-62.

14 Davies H, Bignell GR, Cox C, et al. Mutations of the $B R A F$ gene in human cancer. Nature 2002;417:949-954.

15 Avruch J, Khokhlatchev A, Kyriakis JM, et al. Ras activation of the Raf kinase: tyrosine kinase recruitment of the MAP kinase cascade. Recent Prog Horm Res 2001;56:127-155.

16 Cohen Y, Xing M, Mambo E, et al. BRAF mutation in papillary thyroid carcinoma. J Natl Cancer Inst 2003;95:625-627.

17 Soares P, Trovisco V, Rocha AS, et al. BRAF mutations and RET/PTC rearrangements are alternative events in the etiopathogenesis of PTC. Oncogene 2003;22: 4578-4580.

18 Namba H, Nakashima M, Hayashi T, et al. Clinical implication of hot spot $B R A F$ mutation, V599E, in papillary thyroid cancers. J Clin Endocrinol Metab 2003;88:4393-4397.

$19 \mathrm{Xu}$ X, Quiros RM, Gattuso P, et al. High prevalence of $B R A F$ gene mutation in papillary thyroid carcinomas and thyroid tumor cell lines. Cancer Res 2003;63: 4561-4567.

20 Kimura ET, Nikiforova MN, Zhu Z, et al. High prevalence of $B R A F$ mutations in thyroid cancer: genetic evidence for constitutive activation of the RET/PTC-RAS-BRAF signaling pathway in papillary thyroid carcinoma. Cancer Res 2003;63: 1454-1457.

21 Nikiforova MN, Kimura ET, Gandhi M, et al. BRAF mutations in thyroid tumors are restricted to papillary carcinomas and anaplastic or poorly differentiated carcinomas arising from papillary carcinomas. J Clin Endocrinol Metab 2003;88:5399-5404.

22 Fearon ER, Feinberg AP, Hamilton SH, et al. Loss of genes on the short arm of chromosome 11 in bladder cancer. Nature 1985;318:377-380.

23 Kimura ET, Nikiforova MN, Zhu Z, et al. High prevalence of $B R A F$ mutations in thyroid cancer: genetic evidence for constitutive activation of the RET/PTC-RAS-BRAF signaling pathway in papillary thyroid carcinoma. Cancer Res 2003;63:1454-1457.

24 TrimGen. 'Genetic Technology', (Online) December 2003, 〈http://www.trimgen.com/mutector.htmmutector > mutector.

25 Mazzaferri EL, Jhiang SM. Long-term impact of initial surgical and medical therapy on papillary and follicular thyroid cancer. Am J Med 1994;97:418-428.

26 Mercer KE, Pritchard CA. Raf proteins and cancer: B-Raf is identified as a mutational target. Biochim Biophys Acta 2003;1653:25-40.

27 Tuveson DA, Weber BL, Herlyn M. BRAF as a potential therapeutic target in melanoma and other malignancies. Cancer Cell 2003;4:95-98. 